\title{
Adhesion Studies of Diamond-Like Carbon Films Deposited on Ti6Al4V Alloy after Carbonitriding
}

\author{
Deiler Antonio Lima-Oliveira ${ }^{1}$, Romina Paula Castro Costa ${ }^{2}$, Gislene Valdete Martins ${ }^{3}$, \\ Evaldo José Corat ${ }^{1}$, Vladimir Jesus Trava-Airoldi ${ }^{1}$, Anderson Oliveira Lobo ${ }^{4}$, \\ Fernanda Roberta Marciano ${ }^{4 *}$ \\ ${ }^{1}$ Instituto Nacional de Pesquisas Espaciais, São José dos Campos, São Paulo, Brazil \\ ${ }^{2}$ Faculdade de Ciencia e Tecnologia da Universidade de Coimbra, Coimbra, Portugal \\ ${ }^{3}$ Clorovale Diamantes Indústria e Comércio S.A., São José dos Campos, São Paulo, Brazil \\ ${ }^{4}$ Universidade do Vale do Paraíba, São José dos Campos, São Paulo, Brazil \\ Email: ${ }^{*}$ femarciano@uol.com.br
}

Received December 20, 2011; revised January 17, 2012; accepted January 27, 2012

\begin{abstract}
Diamond-like Carbon (DLC) coatings have attracted significant attention due to their low friction coefficient, high degree of hardness, chemical inertness, and high wear resistance as well as and their many possible uses in metallurgical, aeronautical, and biomedical applications. However, DLC has low adhesion strength to metallic substrates. Carbonitriding was performed before DLC deposition to improve this adherence. Different concentration of nitrogen in the gas mixture was used during the carbonitriding of Ti6Al4V alloy. DLC films were subsequently grown from methane using plasma enhanced chemical vapor deposition. The samples were characterized with Raman scattering spectroscopy, nanoindentation, and tribological tests. Films from $80.0 \% \mathrm{~N}_{2}$ had the best friction coefficient (0.07) and a critical load of $\sim 22 \mathrm{~N}$. In the scratching test, these films had adhesive failure and they completely detached from the substrate only in the end of the tests. SEM images show carbonitring promoted a significant increase in the surface defects (homogeneously distributed) but without the presence of microcracks. EDX analysis indicated that nitrogen element was diffused throughout the thickness of the samples. Hydrogen and carbon atoms from carbonitriding formed a diffusion-barrier layer that can be used as the first step for DLC deposition. This carbonitriding can also provide a carbide layer, which serves as the precursor for the nucleation and growth of DLC films.
\end{abstract}

Keywords: Diamond-Like Carbon; Carbonitriding; Ti6Al4V Alloy

\section{Introduction}

Many attempts have been made to achieve good adherence between diamond-like carbon (DLC) films and titanium alloys, because these films have a wide range of applications. Characterized by low friction coefficient, high wear resistance, and high hardness, the use of DLC coatings in mechanical and electrical applications has increased with recent uses in food, beverage, and medical devices [1-3].

Novel developments have been mainly focused on increasing the relatively low adhesion strength of DLC films on metallic substrates $[2,4,5]$. For this, different methods have been proposed by many research groups $[4,5]$. These methods reduce the residual stress and increase the adhesion of DLC coatings [2]. Some of them are based on a chemically gradient interlayer or a multilayer coating between the substrate material and the DLC film $[2,6,7]$ and others on the direct chemical or physical

\footnotetext{
*Corresponding author.
}

modifications of the carbon coating or on the direct treatments of the substrate surface $[8,9]$.

Plasma nitriding has been performed to increase the surface hardness and wear resistance of austenitic stainless steel $[10,11]$. Analogously, plasma carburizing results in carbon expanded austenite, although typically with significantly lower content of interstitially dissolved carbon compared to nitrogen $[12,13]$. The carbonitriding process, a combination of carburizing and nitriding, is an efficient plasma treatment used to improve the hardness of 316 stainless steel [10]. The carbonitriding of titanium at $700^{\circ} \mathrm{C}$ $-900^{\circ} \mathrm{C}$ leads to a firmly adhered titanium carbide/nitride layer [14]. This study investigated the influence of nitrogen concentration, in the gas mixture, during the carbonitriding of Ti6A14V alloy. DLC films were subsequently deposited and their properties were characterized.

\section{Experimental}

Ti6A14V alloy substrates $\left(2.0 \times 1.0 \times 1.0 \mathrm{~cm}^{3}\right)$ were me- 
chanically polished to a mirror-like finished surface. All the substrates were cleaned ultrasonically in an acetone bath for $15 \mathrm{~min}$, and then dried in a nitrogen atmosphere. The clean samples were mounted on a water-cooled 4.8 $\mathrm{cm}$ diameter cathode powered by a pulsed directly current plasma enhanced chemical vapor deposition power supply, with variable pulse voltage from 0 to $-1000 \mathrm{~V}$ [2].

In the plasma chamber (vacuum base pressure of 1.3 $\mathrm{mPa}$ ), the substrates were additionally cleaned by argon discharge with $20 \mathrm{sccm}$ gas flow at $10.7 \mathrm{~Pa}$ working pressure and a discharge voltage of $-500 \mathrm{~V}$ for $20 \mathrm{~min}$ prior to deposition. The carbonitriding was performed in two steps varying the nitrogen concentration in each step. Table 1 lists the details concerning each gas concentration in the carbonitriding process. The DLC films were deposited using methane as the feed gas to a thickness of around $2.0 \mu \mathrm{m}(20 \mathrm{sccm}$ gas flow at $10.7 \mathrm{~Pa}$ for $2 \mathrm{~h}$ and a discharge voltage of $-700 \mathrm{~V}$ ).

The atomic arrangement of the films was analyzed by using Raman scattering spectroscopy (Renishaw 2000 system) with an $\mathrm{Ar}^{+}$-ion laser $(1=514 \mathrm{~nm})$ in backscattering geometry. The laser power on the sample was $\sim 0.6$ $\mathrm{mW}$ and the diameter of laser spot was $2.5 \mathrm{~mm}$. The Raman shift was calibrated in relation to the diamond peak at $1332 \mathrm{~cm}^{-1}$. All measurements were carried out in air at room temperature.

The DLC morphology and roughness value were characterized by an atomic force microscopy (AFM), VEECO Multimode V, operating in dynamic mode, with $0.01-0.025 \mathrm{O} \mathrm{hm}-\mathrm{cm}$ Antimony (n) doped Si tip (model TESPW).

Composition of the films along their thickness was determined by energy-dispersive X-ray analysis (EDX, Thermoelectrocorporation).

Hardness was measured by the instrumented hardness test, which was carried out using UMT-CETR equipment with a Vickers indenter. The values presented in this study correspond to the average of 10 indentations done at different spots for penetration depths that were shallower than $10 \%$ of the thickness of the films [15].

The friction coefficients and critical loads were determined using a CETR UMT-2H pin-on-disk tribometer under ambient conditions $\left(20^{\circ} \mathrm{C}, 40 \% \mathrm{RH}\right)$. The friction coefficient measurements were carried out, using a sliding speed of $1 \mathrm{~mm} / \mathrm{s}$ while the applied load increased up to $2 \mathrm{~N}$. Titanium alloy ball and the substrates coated with $2.0 \mu \mathrm{m}$-thick DLC films were used to determinate friction coefficient. Scratching tests were conducted using a UMT-CETR with $200 \mu \mathrm{m}$ curvature diamond tip (Rockwell $\mathrm{C} 120^{\circ}$ ). The normal force was increased up to $35 \mathrm{~N}$. The load at which the coating was stripped from the substrate was deemed the critical load $[16,17]$. The coating adhesive strength was determined as a critical load, when intensive acoustic emission occurred, indicating crack propagation [18]. The change of friction force at coating
Table 1. Concentration of each gas during the carbonitriding process.

\begin{tabular}{ccccc}
\hline \multirow{5}{*}{ Carbonitriding parameters } \\
\hline \multirow{2}{*}{$\mathrm{N}_{2}$ Concentration } & Steps & \multicolumn{3}{c}{ Gas flow (sccm) } \\
\cline { 3 - 5 } & & $\mathrm{N}_{2}$ & $\mathrm{H}_{2}$ & $\mathrm{CH}_{4}$ \\
\hline \multirow{2}{*}{$66.7 \%$} & $1 \mathrm{st}$ & 40 & 15 & 5 \\
& $2 \mathrm{nd}$ & 40 & 15 & 20 \\
$75.0 \%$ & $1 \mathrm{st}$ & 60 & 15 & 5 \\
& $2 \mathrm{nd}$ & 60 & 15 & 20 \\
$80.0 \%$ & $1 \mathrm{st}$ & 80 & 15 & 5 \\
& $2 \mathrm{nd}$ & 80 & 15 & 20 \\
$81.8 \%$ & $1 \mathrm{st}$ & 90 & 15 & 5 \\
& $2 \mathrm{nd}$ & 90 & 15 & 20 \\
$83.3 \%$ & $1 \mathrm{st}$ & 100 & 15 & 5 \\
& $2 \mathrm{nd}$ & 100 & 15 & 20 \\
\hline
\end{tabular}

penetration was used as an indication of coating adhesive strength [19].

\section{Results and Discussion}

Raman scattering spectroscopy was used to evaluate the chemical structure of the DLC films (Figure 1). Typical DLC spectra exhibit two distribution bands in the 1000 $1800 \mathrm{~cm}^{-1}$ range. These two bands are defined as the graphite $(\mathrm{G})$ and disorder (D) bands that originate from $\mathrm{sp}^{2}$ sites, because the $514 \mathrm{~nm}(2.4 \mathrm{eV})$ excitation resonates with $\pi \rightarrow \pi^{*}$ transitions at $\mathrm{sp}^{2}$ sites, so that the disorder band will overshadow the contribution of $\mathrm{sp}^{3}$ sites [1]. The D band, appearing approximately at $1345 \mathrm{~cm}^{-1}$, is derived from the relaxation of the D6h point group symmetry of finite graphite crystallites, which allows forbidden modes to show Raman activity. The G band appears approximately at $1535 \mathrm{~cm}^{-1}$ and is associated with the optically allowed E2g mode zone center of crystalline graphite [20].

Figure 1 shows a typical Raman scattering spectrum from DLC film produced after the carbonitriding process. All spectra are very similar and were deconvoluted into $\mathrm{D}$ and $\mathrm{G}$ bands, respectively, using two Gaussian curves [21]. The measured intensity ratio of $D$ and $G$ peak $\left(I_{D}\right.$ $/ \mathrm{I}_{\mathrm{G}}$ ) for these films ranged between 1.2 and 1.4 (see Table 2) and these values do not change significantly according to the concentration of nitrogen during the carbonitriding. They are common values for DLC films and these parameters are empirically correlated to quantities directly related to structural disorder, such as the Young's modulus, the hardness, hydrogen content, and atomic density [21-24]. From these results, the variation of nitrogen content during the carbonitriding does not affect the quality of DLC films.

Figure 2 shows AFM images of the films according to 


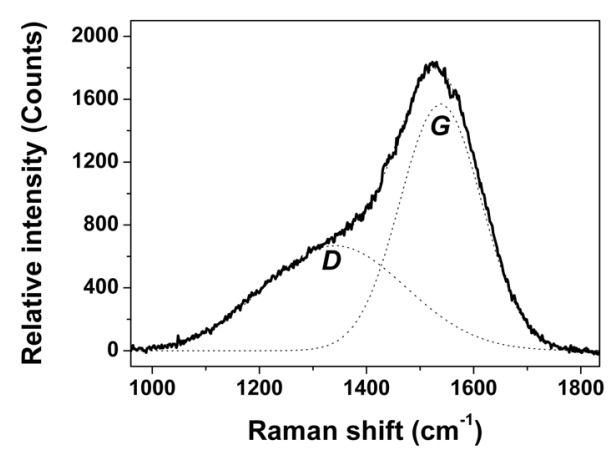

Figure 1. Typical raman scattering spectrum from DLC film produced after the carbonitriding process.

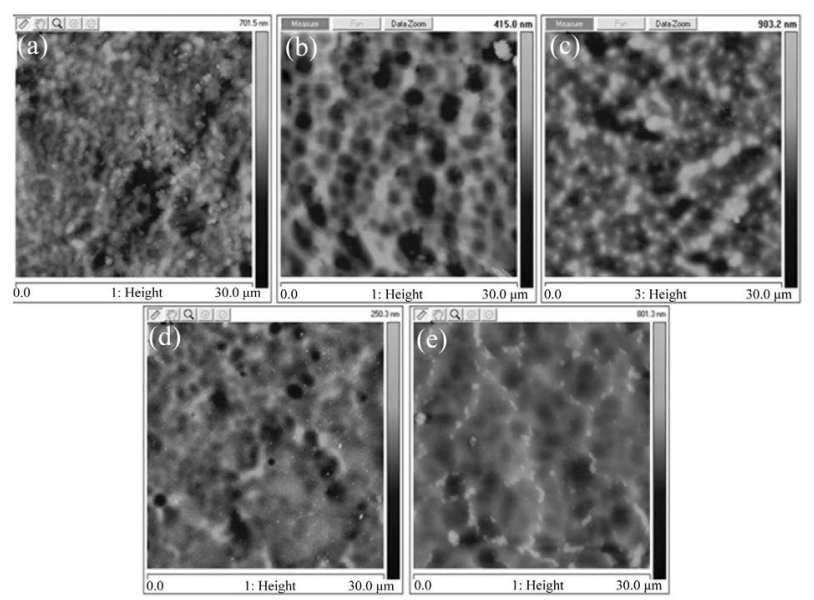

Figure 2. AFM images of the DLC films produced from (a) $66.7 \%$; (b) $75.0 \%$; (c) $80.0 \%$; (d) $81.8 \%$; and (e) $83.3 \%$ nitrogen during the carbonitriding process.

Table 2. Concentration of each gas during the carbonitriding process.

\begin{tabular}{cc}
\hline $\mathrm{N}_{2}$ Concentration & $\mathrm{I}_{\mathrm{D}} / \mathrm{I}_{\mathrm{G}}$ \\
\hline $66.7 \%$ & $1.38 \pm 0.05$ \\
$75.0 \%$ & $1.27 \pm 0.11$ \\
$80.0 \%$ & $1.36 \pm 0.08$ \\
$81.8 \%$ & $1.29 \pm 0.09$ \\
$83.3 \%$ & $1.37 \pm 0.04$ \\
\hline
\end{tabular}

the concentration of nitrogen during the carbonitriding. The average surface roughness (Ra), measured over three different areas of $30 \mu \mathrm{m} \times 30 \mu \mathrm{m}$ each, can be seen on Table 3. According to Fu et al. [25], plasma-treated surface has some micro-level roughness caused by ion bombardment, which may improve the adhesion of the film to the substrate by an anchor effect between them. However, hydrogen pre-etching causes significant coarsening of Ti6Al4V microstructure and severe losses in mechanical properties, such as the impact strength $[25$, 26]. Figures 2(b) and (c) show the biggest holes at the surface and these holes may help to increase the film adhesion.
Table 3. Average surface roughness (Ra) of the DLC films according to the $\mathrm{N}_{2}$ concentration during the carbonitriding.

\begin{tabular}{cc}
\hline $\mathrm{N}_{2}$ Concentration & Average roughness (Ra) \\
\hline $66.7 \%$ & $43.5 \pm 5.5$ \\
$75.0 \%$ & $65.3 \pm 8.3$ \\
$80.0 \%$ & $32.2 \pm 5.6$ \\
$81.8 \%$ & $28.3 \pm 9.8$ \\
$83.3 \%$ & $36.4 \pm 6.7$ \\
\hline
\end{tabular}

Even though all the surfaces are considerably smooth, the authors could not verify any correlation between the average surface roughness and the concentration of nitrogen during the carbonitriding.

Table 4 shows the hardness values as a function of the concentration of nitrogen during the carbonitriding. DLC films over Ti6Al4V had hardness values similar to those deposited over stainless steel substrates $[2,22]$. When the results were compared, hardness values reached a maximum. Hardness is directly correlated with the increase of the atomic density and the decrease of the hydrogen content in DLC films [22]. In addition, the nitriding process provides a diffusion-barrier layer for hydrogen and carbon atoms, with the formation of carbide and saturation of carbon at the substrate surface [25]. The increasing of the sample hardness is due to the nitrided layer probably composed of a mixture of TiN precipitates dispersed in an $\alpha$-Ti (N) matrix [26]. According to Fouquet et al. [27], an increase in treatment temperature, voltage, implanted dose or treatment duration leads to a better quality of the nitride, i.e. a bigger grain size, a higher nitrogen stoichiometry, or a thicker layer.

Some samples started to delaminate from the edges and in the middle, as it shown in Figure 3. In Figure 3(a), it is possible to see only the rest of the coating. Friction tests were only performed on the films that were intact (those produced from $75.0 \%$ and $80.0 \%$ nitrogen during the carbonitriding).

Figure 4 shows the friction coefficient according to the number of cycles for DLC films produced from $75.0 \%$ and $80.0 \%$ nitrogen during the carbonitriding, in ambient conditions $\left(20^{\circ} \mathrm{C}, 40 \% \mathrm{RH}\right)$ to loads of $10 \mathrm{~N}$ for $10.0 \mathrm{~mm} / \mathrm{s}$ of sliding speed. Films from $75.0 \% \mathrm{~N}_{2}$ had an increase of friction coefficient along the time. This means these films were detaching during the test. On the other hand, films from $80.0 \% \mathrm{~N}_{2}$ reached the steady-state friction at 0.07 after 300 cycles and remained approximately constant for the next 900 cycles. Figure 5 shows the friction behavior of these films according to an increasing load. As in Figure 4, both samples had different behaviors. Films from $75.0 \% \mathrm{~N}_{2}$ (Figure 5(a)) had an increasing friction coefficient with the increasing load. The change in the friction coefficient of films from $80.0 \% \mathrm{~N}_{2}$ 
Table 4. Hardness values of the DLC films according to the $\mathbf{N}_{2}$ concentration during the carbonitriding.

\begin{tabular}{cc}
\hline $\mathrm{N}_{2}$ Concentration & Hardness $(\mathrm{GPa})$ \\
\hline $66.7 \%$ & $21.0 \pm 2.0$ \\
$75.0 \%$ & $25.0 \pm 2.7$ \\
$80.0 \%$ & $33.5 \pm 2.5$ \\
$81.8 \%$ & $20.0 \pm 2.1$ \\
$83.3 \%$ & $20.0 \pm 1.7$ \\
\hline
\end{tabular}

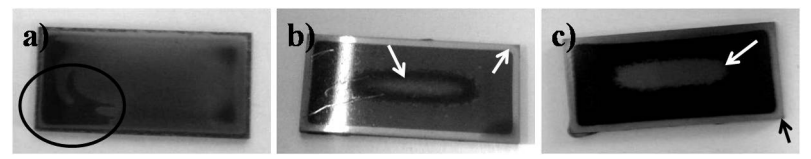

Figure 3. Images of the DLC films produced from (a) $66.7 \%$; (b) $81.8 \%$ and (c) $83.3 \%$ nitrogen during the carbonitriding process.

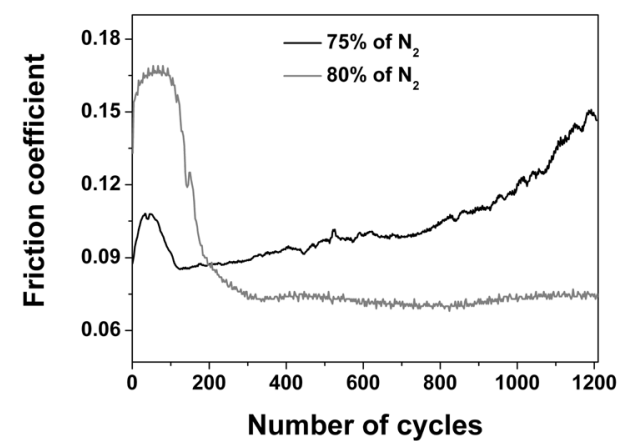

Figure 4. Friction coefficient according to the number of cycles for DLC films produced from (a) $75.0 \%$ and (b) $80.0 \%$ nitrogen during the carbonitriding. These tests were performed in ambient conditions $\left(20^{\circ} \mathrm{C}, 40 \% \mathrm{RH}\right)$ to loads of $10 \mathrm{~N}$ for $10.0 \mathrm{~mm} / \mathrm{s}$ of sliding speed.

(Figure 5(b)) indicates a critical load of $22+2 \mathrm{~N}$. The critical load of films from $75.0 \% \mathrm{~N}_{2}$ was estimated at 12 $+3 \mathrm{~N}$ from the acoustic emission signal (circle line in Figure 6(a)). Films from $80.0 \% \mathrm{~N}_{2}$ did not have any abrupt change in the acoustic emission (as seen in Figure 6(b)). The images of the scratching tracks are shown in Figure 7. In Figure 7(a), from the films deposited from $75.0 \% \mathrm{~N}_{2}$, a spalling failure (total delamination) of the DLC films was observed. In this case, peeling side edges and continuous delamination occurred with complete exposure of the substrate in the track area. The critical load for cohesive failure was identified by an increase in the acoustic emissions produced during the scratching procedure, as illustrated in the circle line of Figure 6(a).

On the other hand, films from $80.0 \% \mathrm{~N}_{2}$ had adhesive failure. In Figure 7(b), sudden detachment of DLC film and peeling side edges was observed in the scratching track. However, an increase in the acoustic emissions was not identified, therefore, the critical load for adhesive failure was defined from optical observations and

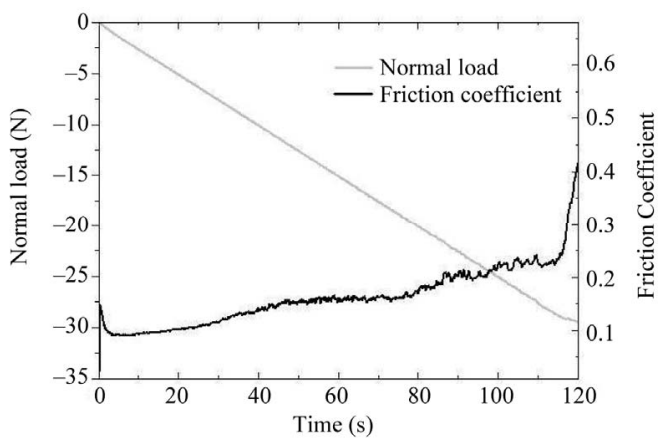

(a)

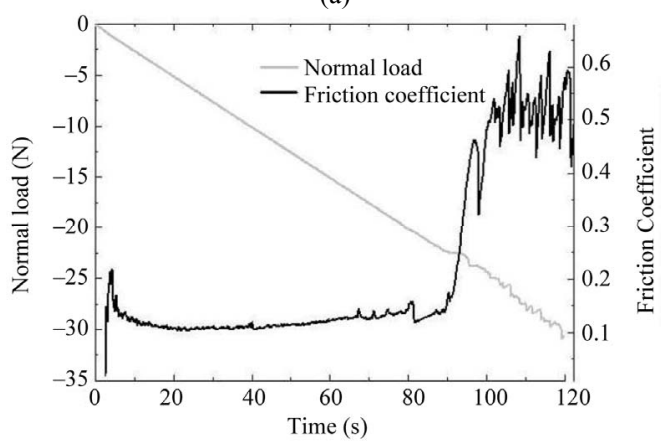

(b)

Figure 5. Friction behavior according to the increasing load for DLC films produced from (a) $75.0 \%$ and (b) $80.0 \%$ nitrogen during the carbonitriding.

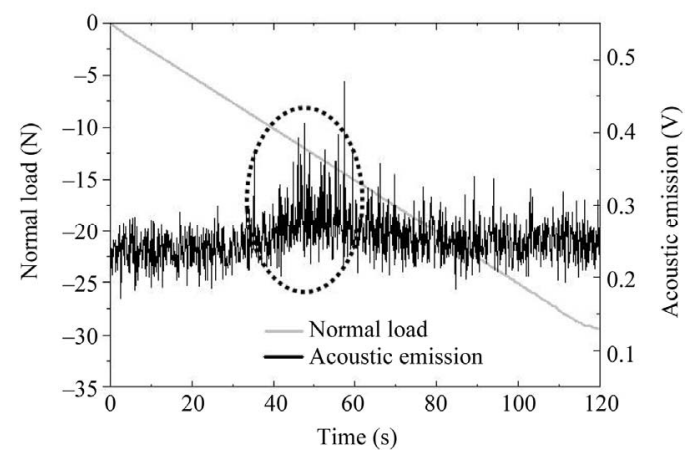

(a)

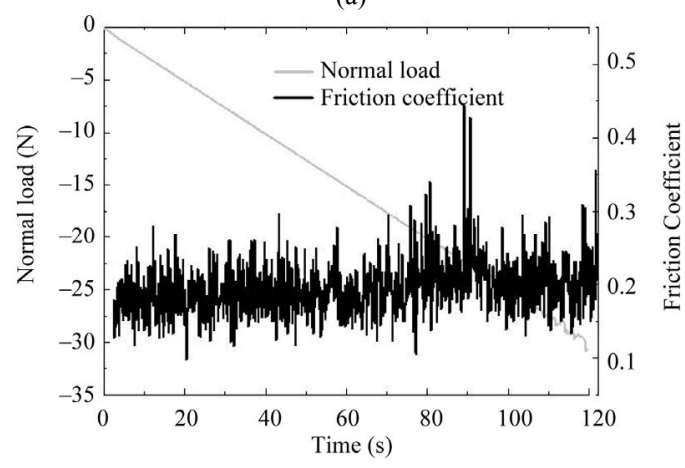

(b)

Figure 6. Acoustic emission signal during the friction tests according to the increasing load for DLC films produced from (a) $75.0 \%$ and (b) $\mathbf{8 0 . 0 \%}$ nitrogen during the carbonitriding. 


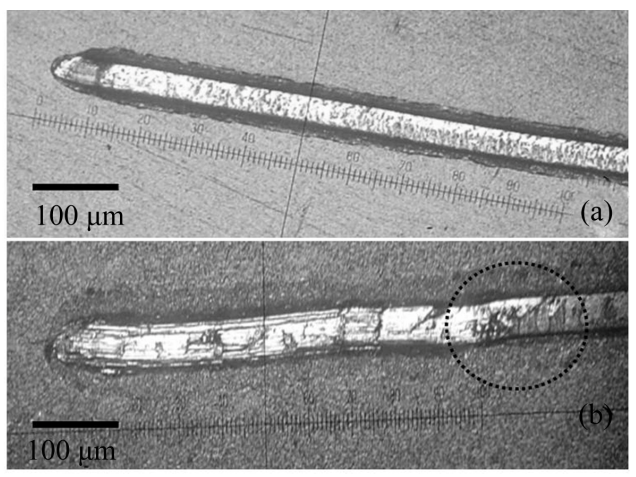

Figure 7. Scratching track of DLC films produced from (a) $75.0 \%$ and (b) $80.0 \%$ nitrogen during the carbonitriding.

with increasing friction coefficient, as illustrated in Figure 5(b). The area inside the circle in Figure 7(b) shows the exact moment when the film detached.

In attempt to investigate the mechanism that explains the best adherence of the films from $80.0 \% \mathrm{~N}_{2}$, SEM images were taken before and after the deposition of these films. Figure 8(a) presents the surface of Ti6Al4V alloy as-received after grinding and polishing and Figure 8(b) shows the alloy surface after carbonitriding with $80.0 \% \mathrm{~N}_{2}$. Carbonitring promoted a significant increase in surface defects (homogeneously distributed) but without the presence of microcracks. This new surface topography formed after carbonitriding may be due to the formation of compounds like titanium carbide and titanium hydride.

Figure 9 shows the EDX analysis according to the sample deepness. The nitrogen element is diffused in the entire thickness of the sample. EDX analysis also indicates that before the nucleation of the DLC film, carbon atoms can quickly diffuse into the substrate. Titanium and its alloys are active carbide/hydride-forming elements. During the carbonitriding process, the estimated surface temperature of the Ti6Al4V substrate using the optical pyrometer is approximately $720^{\circ} \mathrm{C}$. Carbon and hydrogen atoms/ions will easily react with the atoms of the substrate surface and form $\mathrm{TiCN}, \mathrm{TiC}$, and $\mathrm{TiN}$ before the nucleation of DLC films.

The diffusion-barrier layer for hydrogen and carbon atoms formed due to the carbonitriding process can be used as the first step for DLC deposition. The second step of carbonitriding can provide a carbide layer, which serves as the precursor for the nucleation and growth of DLC films.

The optimum composition of $80.0 \%$ nitrogen during the carbonitriding possibly forms a compositionallygraded interlayer that eliminated the interfacial cracking by homogenizing the stress distribution to facilitate good bonding, which improves the load bearing capacity. The carbonitriding process can prevent the rapid diffusion of carbon and hydrogen into the substrate, increasing the

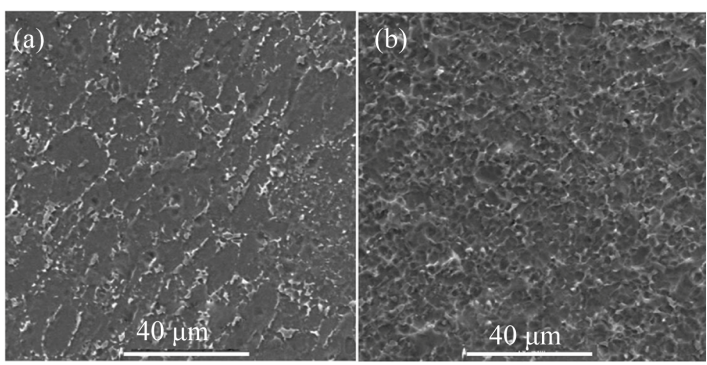

Figure 8. SEM images of Ti6Al4V surface (a) after grinding and polishing and (b) after carbonitriding from $80.0 \% \mathrm{~N}_{2}$.

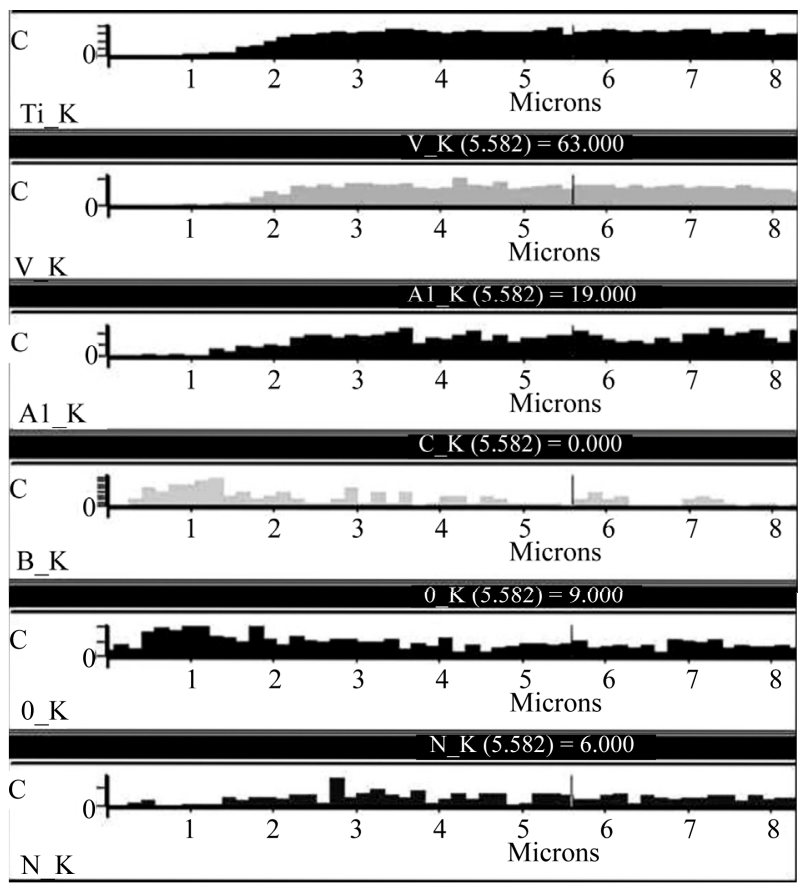

Figure 9. EDX analysis of DLC film produced from $80.0 \%$ $\mathrm{N}_{2}$ during the carbonitriding, according to the sample deepness.

hardening depth, imparting better chemical stability to the titanium alloy substrate, and providing a support layer for wear resistance.

\section{Conclusion}

This manuscript investigated the influence of nitrogen concentration during the carbonitriding of Ti6Al4V alloy. DLC films were deposited over the carbonitrided surface and its properties were evaluated. Raman scattering spectroscopy shows no significant difference between the intensity ratio of $D$ and $G$ peaks $\left(I_{D} / I_{G}\right)$ of these films. Any dependency between the surface roughness and the hardness values was verified according to the nitrogen concentration during the carbonitriding. Tribological tests show films from $80.0 \% \mathrm{~N} 2$ had the best friction coefficient (0.07) and a critical load of $\sim 22 \mathrm{~N}$. In the scratching test, these films had adhesive failure and they were com- 
pletely detached from the substrate only in the end of the tests. SEM images show carbonitring promoted a significant increase on the surface defects (homogeneously distributed) but without the presence of microcracks. EDX analysis indicated that nitrogen element was diffused in the entire thickness of the samples. Hydrogen and carbon atoms from carbonitriding formed a diffusionbarrier layer that can be used as the first step for DLC deposition. This carbonitriding can also provide a carbide layer, which serves as the precursor for the nucleation and growth of DLC films.

\section{Acknowledgements}

The authors are very grateful to Conselho Nacional de Desenvolvimento Científico e Tecnológico (CNPq) and Fundação de Amparo à Pesquisa do Estado de São Paulo (FAPESP) for the financial support.

\section{REFERENCES}

[1] J. Robertson, "Diamond-Like Amorphous Carbon," Materials Science and Engineering: R: Reports, Vol. 37, No. 4-6, 2002, pp. 129-281. doi:10.1016/S0927-796X(02)00005-0

[2] L. F. Bonetti, G. Capote, L. V. Santos, E. J. Corat and V. J. Trava-Airoldi, "Adhesion Studies of Diamond-Like Carbon Films Deposited on Ti6A14V Substrate with a Silicon Interlayer," Thin Solid Films, Vol. 515, No. 1, 2006, pp. 375-379. doi:10.1016/j.tsf.2005.12.154

[3] A. Shirakura, M. Nakaya, Y. Koga, H. Kodama, T. Hasebe and T. Suzuki, "Diamond-Like Carbon Films for PET Bottles and Medical Applications," Thin Solid Films, Vol. 494, No. 1-2, 2006, pp. 84-91. doi:10.1016/j.tsf.2005.08.366

[4] C. Damasceno, S. S. Camargo Jr., F. L. Freire Jr. and R. Carius, "Deposition of Si-DLC Films with High Hardness, Low Stress and High Deposition Rates," Surface and Coatings Technology, Vol. 133-134, 2000, pp. 133-134. doi:10.1016/S0257-8972(00)00932-4

[5] H. Mori and H. Tachikawa, "Increased Adhesion of Diamond-Like Carbon-Si Coatings and Its Tribological Properties, Surface and Coatings Technology, Vol. 149, No. 2-3, 2002, pp. 224-229. doi:10.1016/S0257-8972(01)01449-9

[6] C. Dumkum, D. M. Grant and I. R. McColl, "A Multilayer Approach to High Adhesion of Diamond-Like Carbon Coatings on Titanium," Diamond and Related Materials, Vol. 6, No. 5-7, 1997, pp. 802-806. doi:10.1016/S0925-9635(96)00762-5

[7] M. Stüber, S. Ulrich, H. Leiste, A. Kratzsch and H. Holleck, "Graded Layer Design for Stress Reduced and Strongly Adherent Superhard Amorphous Carbon Films," Surface and Coatings Technology, Vol. 116-119, 1999, pp. 591-598. doi:10.1016/S0257-8972(99)00224-8

[8] T. A. Friedmann, J. P. Sullivan, J. A. Knapp, D. R. Tallant, D. M. Follstaedt, D. I. Medlin and P. B. Mirkarimi, "Thick Stress-Free Amorphous-Tetrahedral Carbon Films with Hardness Near That of Diamond," Applied Physics Letters, Vol. 71, No. 26, 1997, p. 3820.

doi:10.1063/1.120515

[9] B. Kleinsorge, A. Ilie, M. Chhowalla, W. Fukarek, W. I. Milne and J. Robertson, "Electrical and Optical Properties of Boronated Tetrahedrally Bonded Amoprphous Carbon (Ta-C:B)," Diamond and Related Materials, Vol. 7, No. 2-5, 1998, pp. 472-476. doi:10.1016/S0925-9635(97)00238-0

[10] M. Tsujikawa, D. Yoshida, N. Yamauchi, N. Ueda, T. Sone and S. Tanaka, "Surface Material Design of 316 Stainless Steel by Combination of Low Temperature of Carburizing and Nitriding," Surface and Coatings Technology, Vol. 200, No. 1-4, 2005, pp. 507-511. doi:10.1016/j.surfcoat.2005.02.051

[11] M. Tsujikawa, N. Yamauchi, N. Ueda, T. Sone and Y. Hirose, "Behavior of Carbon in Low Temperature Plasma Nitriding Layer of Austenitic Stainless Steel," Surface and Coatings Technology, Vol. 193, No. 1-3, 2005, pp. 309-313. doi:10.1016/j.surfcoat.2004.08.179

[12] T. Christiansen and M. A. J. Somers, "Low Temperature Gaseous Nitriding and Carburising of Stainless Steel," Surface Engineering, Vol. 21, No. 5-6, 2005, pp. 445-455. doi:10.1179/174329405X68597

[13] M. S. Jellesen, T. L. Christiansen, L. R. Hilbert and P. Møller, "Erosion-Corrosion and Corrosion Properties of DLC Coated Low Temperature Gas-Nitrided Austenitic Stainless Steel," Wear, Vol. 267, No. 9-10, 2009, pp. 1709-1714. doi:10.1016/j.wear.2009.06.038

[14] X. M. Li and Y. Han, "Mechanical Properties of Ti $\left(\mathrm{C}_{0.7} \mathrm{~N}_{0.3}\right)$ Film Produced by Plasma Electrolytic Carbonitriding of Ti6Al4V Alloy," Applied Surface Science, Vol. 254, No. 20, 2008, pp. 6350-6357. doi:10.1016/j.apsusc.2008.03.172

[15] X. Cai and H. Bangert, "Hardness Measurements of Thin Films-Determining the Critical Ratio of Deph to Thickness Using FEM," Thin Solid Films, Vol. 264, No. 1, 1995, pp. 59-71. doi:10.1016/0040-6090(95)06569-5

[16] P. J. Burnett and D. S. Rickerby, "The Relationship Between Hardness and Scratch Adhesion," Thin Solid Films, Vol. 154, No. 1-2, 1987, pp. 403-416. doi:10.1016/0040-6090(87)90382-8

[17] M. Blees, G. Winkelman, R. Balkenende and J. M. J. den Toonder, "The Effect of Friction on Scratch Adhesion Testing: Application to a Sol-Gel Coating on Polypropylene," Thin Solid Films, Vol. 359, No. 1, 2000, pp. 1-13. doi:10.1016/S0040-6090(99)00729-4

[18] J. Valli, U. Makela and A. Matthews, "Assessment of Coating Adhesion," Surface Engineering, Vol. 2, No. 1, 1986, pp. 49-49.

[19] A. A. Voevodin, J. M. Schneider, C. Rebholz and A. Matthews, "Multilayer Composite Ceramicmetal-DLC Coatings for Sliding Wear Applications," Tribology International, Vol. 29, No. 7, 1996, pp. 559-570. doi:10.1016/0301-679X(95)00121-J

[20] F. Tuinstra and J. F. Koening, "Raman Spectrum of Graphite," Journal of Chemical Physics, Vol. 53, No. 3, 1970, p. 1126. doi:10.1063/1.1674108

[21] C. Casiraghi, A. C. Ferrari and J. Robertson, "Raman 
Spectroscopy of Hydrogenated Amorphous Carbons," Physical Review B, Vol. 72, No. 8, 2005, p. 385.

doi:10.1103/PhysRevB.72.085401

[22] M. A. Tamor and W. C. Vassell, "Raman Fringerprinting of Amorphous Carbon Films," Applied Physics Letters, Vol. 76, No. 6, 1994, pp. 3823-3830.

doi: $10.1063 / 1.357385$

[23] A. C. Ferrari and J. Robertson, "Interpretation of Raman Spectra of Disordered and Amorphous Carbon," Physical Review B, Vol. 61, No. 20, 2000, pp. 14095-14107. doi:10.1103/PhysRevB.61.14095

[24] V. J. Trava-Airoldi, G. Capote, L. F. Bonetti, J. Fernandes, E. Blando, R. Hübler, P. A. Radi, L. V. Santos and E. J. Corat, "Deposition of Hard and Adherent Diamond-Like Carbon Films inside Steel Tubes Using a Pulsed-DC Discharge," Journal of Nanoscience and Nanotechnology, Vol. 9, No. 6, 2009, pp. 3891-3897.
doi:10.1166/jnn.2009.NS85

[25] Y. Fu, B. Yan and N. L. Loh, "Effects of Pre-Treatments and Interlayers on the Nucleation and Growth of Diamond Coatings on Titanium Substrates," Surface and Coatings Technology, Vo1. 130, No. 2-3, 2000, pp. 173-185. doi:10.1016/S0257-8972(00)00701-5

[26] Y. Q. Fu, B. B. Yan, N. L. Loh, C. Q. Sun and P. Hing, "Deposition of Diamond Coating on Pure Titanium Using Micro-Wave Plasma Assisted Chemical Vapor Deposition," Journal of Materials Science, Vol. 34, No. 10, 1999 , pp. 2269-2283. doi:10.1023/A:1004569406535

[27] V. Fouquet, L. Pichon, A. Straboni and M. Drouet, "Nitridation of Ti6A14V by PBII: Study of the Nitrogen Diffusion and of the Nitride Growth Mechanism," Surface and Coatings Technology, Vol. 186, No. 1-2, 2004, pp. 34-39. doi:10.1016/j.surfcoat.2004.04.006 